\title{
Peer Review of Statistics in Surgical Research: Identify The X-Factor or Toss a Coin!
}

\author{
Ahmed N Ghanem* \\ Department of Urology, Egypt \\ *Corresponding author: Ahmed N Ghanem, Department of Urology, Egypt
}

Received: 疅 April 03, 2019

Published: 制 April 17, 2019

\section{Opinion}

Professor Peter Bacchetti's excellent article [1], highlighting "the other problem of peer review of finding flaws that are not really there based on unfounded statistical criticism, and its demoralizing effect on authors". I wish to add some thoughts to the debated issues. Professor David Horrobin's original classics on the subject $[2,3]$. have not yet been surpassed. It was updated recently [4] and prompted some contributory thoughts [5]. Having enough experience as author of reject articles and some as peer reviewer, I find the most devastating effect to author's morale is making no comment, giving no reason for rejection or not replying all. The BMJ is guilty on this account as an article of mine was rejected that was accepted elsewhere after minor editing [6]. The BMJ, however, is in the good company of most biomedical journals who apply the COPE rules. The article lacked statistics of any kind that perhaps might be one of the reasons it was disliked at BMJ. To Editors' credit, however, it took about a month to say 'No' that caused no momentum loss, unlike other Journals who reach the same verdict on other articles after 6 months or a year that drag another year or two before the author could recover and gather enough time, interest and energy to face the damn thing again. One subtle aim of that article [6], mentioned to BMJ Editors, was an attempt to say that "there is science and in particular evidence based medicine without statistics".

It is a devil's advocate to say statistics has not only been made into a "big lie" but also 'false God'. It was invented elsewhere but currently worshiped only at most medical and surgical journals. A look at Science and Nature testifies such prestigious magazines have reduced statistics to real size and value as a "tool for testing a hypothesis". It is not too basic a question for every biomedical peer reviewer to find out the exact role, aim and limitations of statistics. Some was mentioned in an article [7], nobody noticed save the late great Professor GD Chisholm editor of Br J Urology.
It was based on a study that was rejected by a grant committee. It aimed at resolving 2 of the most serious puzzles of current clinical practice, postoperative hyponatraemia and the multiple vital organ dysfunction or failure syndrome [8]. However, giving data and statistics $[7,8]$. before clarifying the theories [9]. has proved as wrong as putting the cart in front of the horse. Einstein's methods on proposing the special and general relativity theory is the correct way. When statistics was haled in the sixties everyone thought it was the only mean to discover "The Unifying Theory".

This has proved both immensely costly and wrong. The basic fact is 'statistics cannot, was not intended to and will never could, make a discovery'. Observation, mental experiments and the $\mathrm{X}$ factor are the only way to make a discovery long before it is verified and proved by practical studies and statistical tests. Before explaining the X-factor please allow me tell a relevant true story that symbolizes the current problem with statistics. Two friends of mine in UK had a disagreement, made a bit on a round of drinks and decided the first person to enter the hospital club will be the judge. Guess who did? I did but having no clue on how to resolve the conflict suggested that a flip of a coin might be the best way. They agreed also to my condition that while head or tail will determine the winner among them, if the coin stood on edge the judge should be the winner of all. It did and I won. Another conflict started on: Who should buy the 3rd round of drinks? Both agreed that it was my turn. I explained that buying the 3rd round will gain good company but lose all winnings, and my turn should be the 5 th round! The point is statistics can tell the probability of head or tail and exclude the odd but when evaluating to either 0 or $100 \%$ and the truth is known, instead of expiring it generates residual arguments. Professor Richard Smith contributed to this debate by quoting Dr Hedge on Professor Robert Fox's famous thought that "swabbing the rejects with the accepts does not make a difference." 
He added that perhaps it has already been done at BMJ" and asked "How can you know?" With due respect Sir, I frankly think nobody can. Despite a proven incremental value of an average article it does not make a noticeable difference or great loss to scientific advances. Statistically speaking that means a quality article submitted to BMJ has 50\% chance of being accepted or rejected. So, why not save everybody the trouble and toss a coin? Here is where statistics has shot itself in the foot. It gives an average chance to the average and an odd chance to the odd but can't tell which is important. The odd chance of a tossed coin to stand on edge matches that of a breakthrough scientific or medical article coming an editor or peer reviewer's way but detecting such article makes all the difference. Some call it a hunch or gut feeling. Others qualify it by the three-pronged tests of quality, relevance and civility. Identifying the "X-factor" that makes such an article stand out is worth all the trouble. I honestly do not know but it is the arresting beauty found in Einstein's famous papers, Newton's laws, Mozart's music and Shakespeare's writing among many examples that include medicine [2-4]. I wrote 2 articles on such para-scientific para-medical stuff to identify the X-factor, "Rules and lures of the science game" and "The Mozarts of Science" sent to journals nearly two years ago and have not received a reply yet. I think a message of "Ignore the big headed bustard" arrived. Qualified people to find out the X-factor are COPE members. Another question that requires a 'Yes' or 'No' answer would be: if any of Einstein's papers is evaluated using the current peer review standard and statistics adopted by most biomedical journals, would it be accepted?

\section{References}

1. Bacchetti P (2002) Peer review of statistics in medical research: the other problem. BMJ 324(7348): 1271-1273.

2. Horrobin DF (1974) Referees and research administrators: Barrier to scientific research. BMJ 2(5912): 216-218.

3. Horrobin DF (1990) The philosophical basis of peer review and the suppression of innovation. JAMA 263(10): 1438-1441.

4. Stephens WE (1999) Basic philosophy and concepts underlying peer review. Medical Hypotheses 52(1): 31-36.

5. Ghanem AN (2000) Guidelines and Code of Ethics. Saudi Medical Journal 21(7): 694 .

6. Ghanem AN (2002) Features and Complications of Nephroptosis Causing the Loin Pain and Haematuria Syndrome: Preliminary Report. Saudi Med J 23 (2): 197-205.

7. Ghanem AN, Ward JP (1990) Osmotic and metabolic sequelae of volumetric overload in relation to the TURP syndrome. Br J Uro 66(1): 71-78.

8. Ghanem AN (2001) Magnetic field-like fluid circulation of a porous orifice tube and relevance to the capillary-interstitial fluid circulation: Preliminary report. Medical Hypotheses 56(3): 325-334.

9. Ghanem AN (2002) Serum sodium changes during and after transurethral prostatectomy. Saudi Medical Journal 23(4): 477-479.

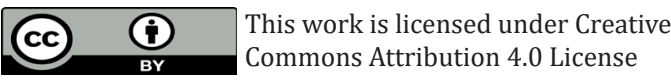

To Submit Your Article Click Here: Submit Article

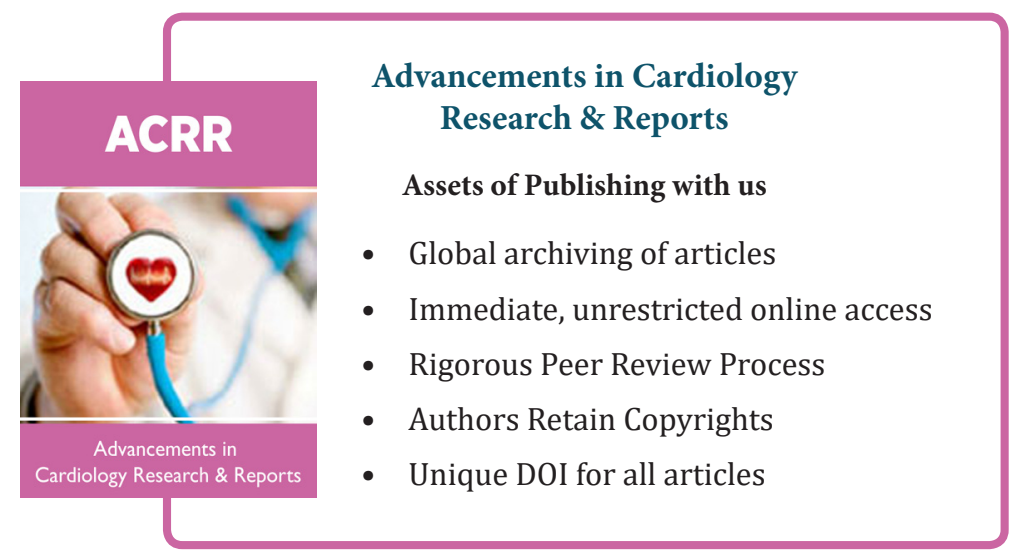

